\title{
АНАЛИЗ БАНКОВСКОЙ СИСТЕМЫ В УСЛОВИЯХ ПАНДЕМИИ
}

\section{ANALYSIS OF THE BANKING SYSTEM IN A PANDEMIC}

S. Azarov

Summary: The article analyzes the conditions of the Russian banking system in the context of a pandemic. The main problems in its development in the context of the crisis manifestations of the coronavirus pandemic were identified. Based on the results of the study of the article, it can be concluded that it is necessary to change the conceptual approach to the formation of the banking system, from the point of view of the provision of credit resources and their availability in individual sectors of the Russian economy. The effective mechanisms and strategies for overcoming negative trends in the banking system of Russia in a pandemic are considered.

Keywords: banks, system, pandemic, coronavirus, debt capital, economy.
Азаров Сергей Вадимович

Аспирант, Московский университет имени С.Ю. Buтmе,

2. Москва

sergey1995a@yandex.ru

Аннотация: В статье проведен анализ условий деятельности банковской системы России в условиях пандемии. Были определены основные проблемы в ее развитии в условиях кризисных проявлений пандемии коронавируса. На основании результатов исследования статьи можно сделать вывод про необходимость изменений концептуального подхода к формированию банковской системы, с точки зрения обеспеченности кредитными ресурсами и их доступности по отдельным отраслям экономики России. Рассмотрены эффективные механизмы и стратегии преодоления негативных тенденций в банковской системе России в условиях пандемии.

Ключевые слова: банки, система, пандемия, коронавирус, заемный капитал, экономика.

\section{Введение}

$\mathrm{B}$ анковские системы всех без исключения стран мира характеризуются финансовой уязвимостью по отношению к внешним шокам и ограниченными возможностями по абсорбированию рисков. С наибольшей силой это проявляется в периоды кризисов, когда банки сталкиваются с угрозой потери капитала и ликвидности. Наряду с уменьшением притока клиентских средств усиливается их отток, имеющий во многих случаях хаотичный характер. Высокие темпы роста проблемной и просроченной ссудной задолженности усиливают давление на показатели достаточности капитала. В периоды кризисов вследствие кредитного сжатия и ухудшения качества ссудных портфелей происходит значительное, а во многих случаях обвальное, снижение процентных и непроцентных доходов банков. Вследствие этого повышается вероятность образования убытков и появления угрозы прекращения деятельности. Как показывает мировой опыт, экономические и финансово-банковские кризисы идут во многих случаях рука об руку, дополняя и даже усиливая друг друга. При этом в числе наиболее пострадавших секторов уже на первой фазе экономического кризиса во многих случаях оказывалась именно банковская сфера. Во избежание угрозы реализации системных рисков государствами и регуляторами при участии или в лице центральных банков почти всегда в первоочередном порядке принимались меры по купированию и преодолению кризисных процессов именно в банковском секторе.

Большой вклад в разработку научных проблем повы- шения эффективности взаимодействия финансового и реального секторов российской экономики, более полного использования банковского кредита на развитие экономики внести труды О.И. Лаврушина [1-3], Ю.Ю. Толмачевой [4] и др. Однако коронавирусный аспект проблем взаимозависимости банковской системы и экономики России остается не до конца исследованным.

Цель данного исследования - проведение анализа банковской системы в условиях пандемии.

\section{$* * *$}

Охвативший практически все страны мира экономический кризис, «спусковым крючком» которого послужила пандемия коронавирусной инфекции, наибольший ущерб наносит пока населению и нефинансовым предприятиям [4]. Введение в национальных масштабах карантинных мер и режима самоизоляции (локдауна) привело к снижению деловой активности во многих сферах реальной экономики вплоть до временного прекращения деятельности.

В сложившихся условиях критически важное значение приобрело бесперебойное функционирование систем расчетно-кассового обслуживания и оказания всего комплекса финансовых услуг - от проведения платежей до оказания кредитной поддержки. Выполнение этих функций легло главным образом «на плечи» банковских систем, которые тем самым вносят заметный вклад в преодоление экономических последствий новой коронавирусной инфекции. Даже на пике первой волны 
пандемии COVID-19 офисы и отделения российских банков продолжали обслуживать клиентов. Для сохранения доступа к наиболее важным услугам в ситуации вынужденной самоизоляции банки предлагают широкие возможности использования онлайн-сервисов, в том числе по управлению счетами, конвертации валют, платежам и переводам [5].

Ключевые тренды развития банковской системы всегда определяются комбинированным действием долгосрочных и краткосрочных факторов, включающих в себя как текущие макроэкономические и социально-политические условия, так и изменения законодательной и институциональной среды, которые задают векторы развития различных групп кредитных организаций [1-3].

Наряду с фундаментальными характеристиками, оказывающими долговременное влияние на параметры банковской деятельности, в каждый конкретно взятый момент времени могут возникать кризисные аномалии, устранение которых требует принятия оперативных и нестандартных решений. Именно такая ситуация сложилась к марту 2020 года, когда пандемия COVID19 изменила условия функционирования как российской экономики в целом, так и ее банковского сектора. К началу августа 2020 года совокупные активы банковского сектора после сжатия в апреле и мае даже превзошли докризисный уровень, превысив 105 трлн руб. Весомый вклад в восстановление и поддержание положительной динамики банковской индустрии внесли системно значимые кредитные организации (СЗКО), удельный вес которых достигает почти 70\% активов этого сектора экономики.

Особенностью текущего кризиса в России является то, что в отличие от кризисов 2008-2009 и 2014-2015 годов поддержка банковского сектора на начальном его этапе не входила в число первоочередных задач и приоритетов экономической политики государства. Напротив, кредитные и финансовые организации участвуют в реализации общегосударственных мер по преодолению последствий новой коронавирусной инфекции для населения и бизнеса [6].

Принят специальный закон об условиях кредитных каникул, введен регламент беспроцентных кредитов на выдачу заработной платы, запущены «антикризисные» программы кредитования малого и среднего предпринимательства, системообразующих предприятий по пониженной ставке, а также льготного ипотечного кредитования. Весомую роль в сохранении системной устойчивости банковского сектора играют регуляторные послабления и действия Банка России по поддержанию текущей ликвидности.

Однако в значительной степени системная устойчи- вость сектора обеспечивается ее участниками - банками и небанковскими кредитными организациями за счет их прибыли. К началу пандемического шока большинство российских банков подошло с запасом капитала.

Проводимая Банком России работа по оздоровлению банковского сектора была завершена в целом к концу 2019 года. Тем не менее, в российской банковской системе сохраняется уже ставший хроническим достаточно высокий по мировым меркам (как минимум, около 9-10\% всего кредитного портфеля предприятий и населения) уровень проблемной и просроченной задолженности. По итогам II квартала 2020 года банки получили прибыли (до налогообложения) в объеме 176 млрд руб. (что меньше результатов января- марта (611 млрд руб.) в 3,5 раза, а аналогичного периода прошлого года - в 2,4 раза - рис. 1. Таким образом, влияние пандемии оказалось достаточно сдержанным, и она пока не привела к массовым убыткам банков. Вместе с тем, без учета прибыли Сбербанка (125 млрд руб.), положительный финансовый результат банковского сектора за II квартал 2020 года оказался куда скромнее - всего 51 млрд руб.

На динамику прибыли банков повлияло ухудшение качества активов банков: в первом полугодии значительно выросли убытки от создания резервов. Так, без учета Сбербанка и санируемых банков, потери от досоздания резервов в текущем году составили 393 млрд руб., что практически в 9 раз превышает результат за аналогичный период прошлого года (44 млрд руб.).

На рис. 2 представлена динамика стоимости акций российских банков в период коронокризиса [3].

Объем досозданных резервов был бы выше, но помогли реструктуризации кредитов населению и предприятиям. Так, с конца марта по середину июля реструктурированная задолженность в портфеле кредитов крупного бизнеса достигла 10\%, МСБ - 14\%. Самой низкой остается доля реструктуризаций в розничном портфеле - 3,6\%.

Значительная часть банков имеет ограниченные возможности для создания дополнительного запаса капитала и пополнения текущей ликвидности. Прибыль, показатели рентабельности капитала и активов крайне неравномерно распределены между различными группами банков. По данным Рейтингового агентства «Эксперт РА», медианная рентабельность балансового капитала всех кредитных организаций по итогам последних четырех кварталов установилась на уровне 5,35\%, существенно сократившись относительно предшествующих сопоставимых периодов (7,86\% за период с 01.07.2018 по 01.07.2019 и 6,98\% за 2019 год) в результате снижения денежных потоков и роста потерь от реализации кредитных рисков на фоне пандемии. 


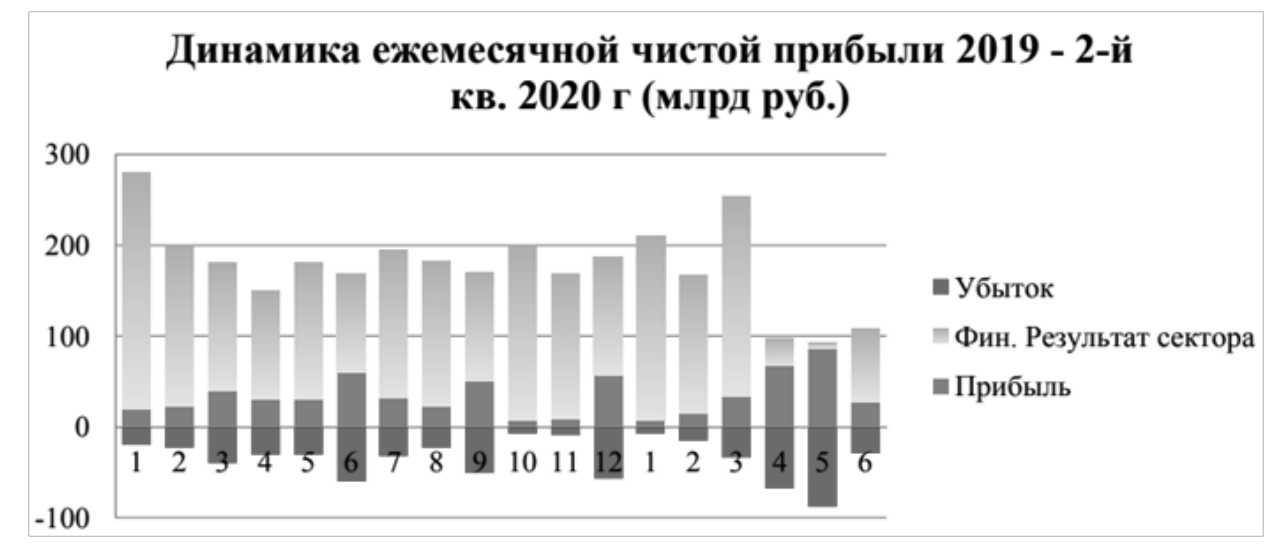

Рис. 1. Динамика чистой прибыли банковского сектора

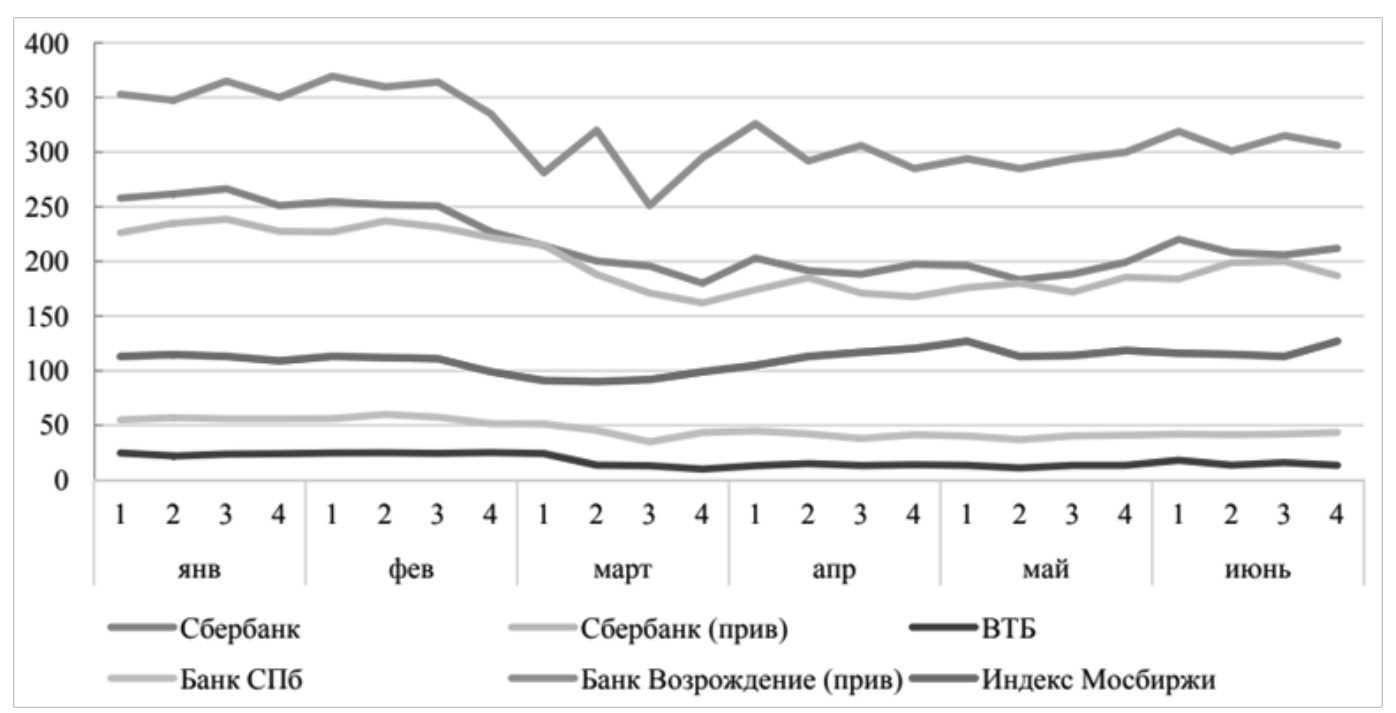

Рис. 2. Акции российских банков в период коронокризиса [3]

Благодаря новому механизму санации и докапитализации ряда крупных банков удалось устранить угрозу реализации системных рисков. Уже в течение трех последних лет в России сохраняется структурный профицит ликвидности, хотя размер его и снизился. В целом по системе риски потери текущей ликвидности пока не являются существенными.

Фондирование банков в основном осуществляется за счет привлечения средств граждан и предприятий, номинированных в рублях, что снижает их зависимость от валютной ликвидности и внешнего финансирования. Особого упоминания заслуживают региональные банки. Наличие сильных региональных банков дает клиентам возможность более широкого выбора услуг, что особенно важно для малого и среднего регионального бизнеса. Значимым фактором развития региональных игроков могут стать программы государственной поддержки как на федеральном, так и на местном уровне, в том числе благодаря установлению более лояльных требований по рейтингам, необходимых для участия в них.
На текущий момент по многим госпрограммам установлены запретительные уровни рейтингов, которые не позволяют крепким региональным 6 игрокам принимать в них участие, что дополнительно сокращает их клиентскую базу и ослабляет конкурентные позиции. Увеличение количества региональных банков, которые участвуют в госпрограммах, позволит им реализовать свои конкурентные преимущества и удержать клиентскую базу, что позитивно отразится на качестве и уровне доступности банковских услуг для населения и МСБ в регионах. Региональные банки и банки с базовой лицензией небольшие, но работают в более тесном контакте с клиентами на местах и муниципальными органами, чем их дальше ушедшая в цифровизацию группа СЗКО. Основной костяк их клиентов - это субъекты МСП, их работники и их семьи. И это основной их банковский бизнес, их рыночная ниша - кредиты предприятиям и розничные, вклады и депозиты, зарплатные проекты.

Большинство реализуемых или планируемых сейчас Правительством и Банком России программ поддержки экономики и граждан не предусматривают участие ма- 
лых региональных банков. При этом не учитывается тот факт, что самые большие сложности у клиентов сейчас как раз в регионах, во многих населенных пунктах, где попросту отсутствуют представительства федеральных банков и доступ к финансовым услугам обеспечивают только региональные кредитные организации, а механизм льготного фондирования таких банков не выработан до сих пор. При этом в программах субсидирования кредитный риск на банк отсутствует в принципе.

В тоже время стоит отметить трудности в достижении построения стабильной и эффективной системы обеспечения кредитными ресурсами предприятий и компаний различных отраслей экономики России в условиях пандемии, которые обусловлены нижеприведенными факторами:

1. Банковская система страны, находится в стадии структурной перестройки, результатом которой стало резкое снижение количества самостоятельных банков, зарегистрированных на территории субъектов Российской Федерации, совет директоров и органы исполнительной власти которых находятся на территории размещения клиентов банка: вкладчиков и заемщиков.

2. Ресурсов банковской системы регионов (региональных банков и иногородних филиалов) не достаточно не только для развития экономики отдельных субъектов Российской Федерации, но и для поддержания сложившейся потребности организаций в краткосрочных кредитных ресурсах.

3. Недостаточное получение кредитов от банков предприятиями различных субъектов Российской Федерации на формирование оборотных средств может привести к платежному кризису, о чем свидетельствуют данные о нарастающем превышении кредиторской задолженности над дебиторской задолженностью.

4. Банковская система различных субъектов Российской Федерации не обеспечивает экономику регионов источниками долгосрочных инвестиций в основные фонды и, соответственно, обновления основных фондов предприятий различных субъектов Российской Федерации.

5. Главным источником для кредитных вложений являются вклады населения, проживающего в различных субъектах Российской Федерации. Данный источник составляет свыше 70\% средств клиентов банков, привлеченных в банковскую систему различных субъектов Российской Федерации.

6. Средства бюджетов различных субъектов Российской Федерации, направляемые в экономику регионов, не являются определяющими и достаточными для развития экономики регионов. Они составляют менее $20 \%$ доходов консолидированного бюджета области и не многим более 6\% от средств населения, аккумулированных банковским сектором региона.

7. Существующая институциональная структура банковского сектора не создает финансовой устойчивости и стабильности экономики различных субъектов Российской Федерации. Соотношение показателей региональных банков и филиалов иногородних банков по количеству единиц на территории различных субъектов Российской Федерации составляет, как правило, 1 к 6, по кредитам юридическим лицам 1 к 10. При незначительном собственном капитале региональных банков (собственным капиталом филиалы, как известно, не наделяются) сохраняется ситуация повышенных кредитных рисков и рисков финансовой устойчивости в различных субъектах Российской Федерации.

8. Отсутствует научно обоснованный подход к определению потребности в банковских услугах на территориях различных субъектов Российской Федерации. Применяемая в настоящее время Банком России методика оценки обеспеченности банковскими услугами регионов есть не что иное, как определение фактической средней величины обеспеченности услугами в регионе и соотношения этой средней со средней величиной обеспеченности по России.

Главное, что удалось сделать к настоящему времени - это не допустить реализации негативного сценария развития событий и адаптировать работу банковского сектора к условиям коронавирусной пандемии. Однако предстоит еще пройти восстановительный период как экономике в целом, так и банковскому сектору в частности, длительность, которого пока трудно оценить.

C приходом пандемии COVID-19 банковская система Российской Федерации, которая считалась устойчивой и стабильной, оказалась не готовой к функционированию в новых реалиях. Банки вынуждены изменить стратегию расширения и развития на стратегии выживания. Сокращая административные затраты, банки, в первую очередь, начали активно сокращать количество отделений. Сегодня тренд стремительного спада меняется на постепенное восстановление и рост. Поэтому перед банками встала следующая проблема - каким образом оптимизировать свою филиальную сеть, чтобы она приносила максимальную прибыль, и определять перспективные города для открытия новых филиалов, ведь времена необдуманного роста и наращивания сети отделений остались в прошлом.

\section{Выводы}

Пандемия вирусной инфекции COVID-19 поставила банковский сектор в непростые условия существования, 
требующие изменения принципов ведения бизнеса и влекущие за собой финансовые потери.

Первостепенного внимания потребует решение проблемы реструктуризации ссудной задолженности как в разрезе различных сегментов кредитования, так и отдельных отраслей и подотраслей экономики. В этой связи целесообразно не снимать с повестки дня вопросы изменений законодательных основ досудебного и судебного урегулирования задолженности, а также либо создания специального фонда (агентства) реструктуризации «плохих» активов, либо возложение этих функций на уже существующие структуры.

Самостоятельной проработки заслуживает вопрос об источниках покрытия возможных убытков, в том числе в тех случаях, когда предоставлялись соответствующие гарантии и поручительства. Не исключено, что в повестку дня может быть поставлен вопрос о достаточности капитала. В кризисные периоды даже надежные заемщики могут испытывать сложности с обслуживанием ссудной задолженности. Кредитные каникулы также на практике приведут к увеличению проблемной и просроченной задолженности.
Снижение качества кредитных портфелей потребует на выходе из кризиса досоздание резервов на возможные потери по ссудам. Под этим углом зрения заслуживает внимания постановка вопроса о подготовке третьей по счету после 2008-2009 годов программы докапитализации (рекапитализации) банковского сектора. Ее запуску должно предшествовать обобщение опыта программ 2010 и 2015 годов. Важно обеспечить доступ к бюджетным средствам, выделяемым на цели докапитализации, не только банкам с государственным участием, но и частным банкам при условии, что часть средств в обязательном порядке будет внесена собственниками банков.

Таким образом, на основании результатов исследования статьи можно сделать вывод про необходимость изменений концептуального подхода к формированию банковской системы, с точки зрения обеспеченности кредитными ресурсами и их доступности по отдельным отраслям экономики России. Она должна обладать признаками финансовой самостоятельности. Предлагаются критерии оценки достаточности сегмента банковской системы в виде доли (квоты) банковского капитала в совокупности капитала кредитных организаций, расположенных в различных субъектах Российской Федерации.

\section{ЛИТЕРАТУРА}

1. Лаврушин О.И. Эволюция теории кредита и его использование в современной экономике. М.: Кнорус, 2016. 394 с.

2. Лаврушин 0.И. Банки в современной экономике: необходимость перемен // Банковское дело. 2013. № 4. С. 6-13.

3. Толмачева, Ю.Ю. Чем обернется пандемия для банковской системы РФ // Экономический форум.-2020.-№1.-С.116-119.

4. Как рынок оценил влияние пандемии на российские банки // Финансовая газета [Электронный ресурс]. - Режим доступа: https://fingazeta.ru/finance/ banki/465384 (дата обращения: 02.12.2020).

5. Обзор финансовой стабильности Банка России за конец 2019-начало 2020 гг. [Электронный ресурс]. - Режим доступа: https://www.cbr.ru/Collection/ Collection/ File/27911/0FS_20-01.pdf (дата обращения: 02.12.2020).

6. Финансовый портал Investing.com. Котировки акций российских компаний. [Электронный ресурс]. - Режим доступа: https://ru.investing.com/markets/ (дата обращения: 02.12.2020).

7. Попова Ирина Николаевна, Пономарев Антон Павлович Проблемы банковской деятельности в условиях пандемии // StudNet. 2020. №8. URL: https://cyberleninka.ru/article/n/problemy-bankovskoy-deyatelnosti-v-usloviyah-pandemii (дата обращения: 02.12.2020).

(c) Азаров Сергей Вадимович (sergey1995a@yandex.ru).

Журнал «Современная наука: актуальные проблемы теории и практики» 